\title{
Alpha-Synuclein: The Interplay of Pathology, Neuroinflammation, and Environmental Factors in Parkinson's Disease
}

\author{
Songzhe He $\mathrm{He}^{\mathrm{a}, \mathrm{b}}$ Shan Zhong ${ }^{\mathrm{c}}$ Gang Liu ${ }^{\mathrm{c}}$ Jun Yang ${ }^{\mathrm{a}}$ \\ ${ }^{a}$ Clinic Laboratory Department, Affiliated Hospital of Guilin Medical University, Guilin, China; ${ }^{b}$ Department of \\ Neurology, Nanfang Hospital, Southern Medical University, Guangzhou, China; ' Department of Acupuncture, \\ Guilin Hospital of Traditional Chinese Medicine, Guilin, China
}

\section{Keywords}

a-Synuclein · Parkinson's disease · Protein aggregation ·

Neuroinflammation · Environmental factors

\section{Abstract}

Background: Parkinson's disease (PD) is a multifactorial, chronic, and progressive neurodegenerative disease. a-Synuclein (a-syn), which is the main protein component of Lewy bodies, plays an important role in the pathological hallmarks of PD. However, the pathological function of a-syn and the molecular mechanisms responsible for the degeneration of dopaminergic neurons are still elusive. Summary: Cumulative evidence implicates that abnormal processing of a-syn will be predicted to lead to pathological changes in PD. Key Messages: In this review, we summarize the structure and physiological function of a-syn, and further discuss the interplay of pathology, neuroinflammation, and environmental factors in PD. Additionally, we suggest future directions for understanding the toxicity of a-syn to neurons, which may ultimately encourage us to better design diseasemodifying therapeutic strategies for PD.

\section{Introduction}

Parkinson's disease (PD) is a progressive neurodegenerative disorder that is characterized by the classical motor features of parkinsonism related to Lewy bodies (LBs) and loss of dopamine (DA) neurons in the substantia nigra $[1,2]$. According to the UK Parkinson Disease Society Brain Bank, the diagnosis is based on the presence of the clinical history and motor symptoms (including resting tremor, bradykinesia, and rigidity as the most characteristic) [3]. Currently, the exact pathogenesis of $\mathrm{PD}$ is elusive, which may be related to oxidative stress, mitochondrial dysfunction, cellular senescence, and epigenetic alterations [4-6]. In the process of normal metabolism, cells can produce reactive oxygen species (ROS) such as hydroxyl radical $\left(\mathrm{OH}^{-}\right)$, hydrogen peroxide $\left(\mathrm{H}_{2} \mathrm{O}_{2}\right)$, and so on. Protein, DNA, and phospholipids of the cell membrane are easily oxidized by ROS, which leads to cell dysfunction, metabolic disorder, and even death. There are defects in the antioxidant system of PD patients, and the ability of ROS scavenging is decreased, while the DA neurons in the substantia nigra and stria-

S.H. and S.Z. contributed equally to this work. 
tum are hyperoxic and are more sensitive to oxidative stress. Furthermore, due to the increase of ROS, it is easy to damage the mitochondrial protein and DNA, which may cause the variation of mitochondrial DNA (mtDNA), decrease the activity of mitochondrial respiratory chain complex I and decrease the synthesis of adenosine triphosphate (ATP), resulting in the degeneration and loss of DA neurons due to lack of energy, and finally death [7]. Meanwhile, abnormal expression and aggregation of $\alpha$-synuclein ( $\alpha$-syn), which is the main protein component of LBs, plays an important role in the pathological hallmarks of PD and other synucleinopathies $[8,9]$.

In this review, we summarize the available evidence describing the physiological structure of $\alpha$-syn, and further discuss the interplay of pathology, neuroinflammation, and environmental factors in PD, and how $\alpha$-syn is intricately involved in many neural functions, including mitochondrial homeostasis. Understanding how the different structural forms of $\alpha$-syn affect neuropathology, it may ultimately encourage us to better design diseasemodifying therapeutic strategies for PD.

\section{Characteristic Structural Features and Function of a-syn}

a-syn consists of 140 amino acids (aa) and is divided into three regions: a positively charged N-terminal region (1-60 aa), a central hydrophobic region (61-95 aa) with the non-amyloid-beta component, and a highly acidic C-terminal domain (96-140 aa) [10-12]. Under physiological conditions, $\alpha$-syn exists mainly in the substantia nigra, cortex, and hippocampus, and plays an important role in synaptic function and plasticity [13]. Except for the brain, $a$-syn is also expressed in the heart, muscle, and other tissues, where it maintains calcium homeostasis in mitochondria through the modulation of the endoplasmic reticulum and mitochondrial membranes [14]. Although a-syn is also found in biological fluids such as cerebrospinal fluid, blood, and plasma, there is an ongoing debate about the use of $a$-syn as a biomarker for diagnosis, and the quantification of $\alpha$-syn in cerebrospinal fluid and blood has failed to produce consistent results $[15,16]$.

In addition, the other synuclein members $\beta$ - and $\gamma$-synuclein are two isomers of $\alpha$-syn, which also belong to the small molecular non-structural protein family $[17$, 18]. According to previous studies, although $\beta$ - and $\gamma$-synuclein proteins are not found in LBs, both of them are related to the hippocampal axonal pathology of PD and dementia with Lewy bodies $[19,20]$. Besides, a change in the expression of $\gamma$-synuclein has also been specifically observed in enhanced metastasis and cancer drug resistance [21].

a-syn is mainly related to the central nervous system (CNS), but it has also been reported to exist in non-neuronal tissues. The involvement of lipid membranes is reported in the function and pathological properties of a-syn [22]. Using immunohistochemistry (IHC) and mass spectrometry tissue imaging (MALDI-MSI), $a$-syn can sense lipid accumulation defects and induce lipid lateral expansion, leading to membrane remodeling. Similarly, Akerman et al. [23] also adopted the above method (IHC and MALDI-MSI) to analyze the expression and localization of neurodegenerative disease-related proteins in fresh frozen human skin specimens, showing that $\mathrm{A} \beta_{34}$ in human skin may represent a stable intermediate of $A \beta_{40}$ and $A \beta_{42}$ degradation pathway, which will provide an important new insight for the existence of neurodegenerative disease-related targets in human skin. Altogether, these data suggest that even though the precise physiological function of $\alpha$-syn is unclear, the expression of $\alpha$-syn in non-neuronal tissues may be a new direction of future research.

\section{Misfolding and Aggregation of a-syn: Implications in PD Pathogenesis}

Misfolding and aggregation of proteins are often considered to be a consistent pathological feature of neurodegenerative disorders $[24,25]$. In order to understand the role of $\alpha$-syn in mediating the pathogenesis of $\mathrm{PD}$, the researchers studied $\alpha$-syn knockout mice and found that although they showed some defects in the nigrostriatal DA pathway, they could survive and give birth without any abnormalities or characteristics of PD [26]. This study suggests that $\mathrm{PD}$ is caused by the acquisition of toxic function of $\alpha$-syn, not by the loss of its normal function. The gain of toxic function of $\alpha$-syn is related to the accumulation of $\alpha$-syn, which leads to its aggregation. In addition, the changes of SNCA gene expression caused by gene duplication, triplication or mutations aggravate the accumulation of misfolded $\alpha$-syn. This phenomenon prompted the researchers to study in detail the aggregation pathway of $a$-syn in vitro. As a result, these studies support the hypothesis that accelerated fibrillation of $\alpha$-syn is the cause of early-onset PD [27-29]. 
Neurodegenerative diseases are characterized by the accumulation of misfolded proteins inside or outside the cell. In the past decade, researchers have found that these disease-related pathological proteins undergo cell-to-cell transmission [30-32]: after transmission to the recipient cells, the pathological proteins act as templates to induce the misfolding of their normal endogenous corresponding proteins, leading to the amplification of the pathological protein conformation, known as "templated amplification" (cell-to-cell transmission of pathological proteins). It is well known that recombinant synthetic $\alpha$-syn can aggregate in vitro to form fibrils similar to those found in vivo [33]. These preformed fibrils (PFF) can spread in a prion-like manner in neuron culture in vitro, and when injected into mouse brain, they can also spread in a prionlike manner in vivo, forming pSer129- $\alpha$-syn-positive LBlike inclusion bodies, thus inducing PD [34]. According to the Braak hypothesis [35, 36], the researchers injected synthetic misfolded $\alpha$-syn PFF into the muscular layers of the pylorus and duodenum of mice (these muscle layers were densely innervated by the vagus nerve) to mimic the transmission of pathological $a$-syn, which finally confirmed the viewpoint that pathological $\alpha$-syn could be transmitted from the intestinal tract to the brain [37].

To date, six dominant mutations (A30P, E46K, A53T, A53E, H50Q, G51D) and a recently announced A53V have been reported, which are genetically associated with a familial form of PD [38-44]. It is well known that A30P and A53T mutations show early oligomerization, which are also hallmarks of early-onset PD [45]. Recently, however, a new familial mutation $\mathrm{A} 53 \mathrm{~V}$ has been found in the Japanese population associated with late-onset PD [44]. These findings suggest that each mutation can show a unique mechanism, leading to the occurrence and development of the disease. Except for the aggregation of $\alpha$-syn itself, $\alpha$-syn also makes some effects on ubiquitin, tyrosine hydroxylase, heat shock protein, and autophagosome protein [46-49]. In their study, through nine site-specifically ubiquitin-modified $\alpha$-syn derivatives, Meier et al. [50] demonstrated that different ubiquitination sites could bring different effects on the aggregation of a-syn. Furthermore, in the cellular model, Lewy bodylike $\alpha$-syn aggregates impair the overall macroautophagy by reducing autophagosome clearance, which may contribute to an increase in cell death [49]. Nevertheless, although a growing body of evidence suggests that aggregation of a-syn may be impaired in many neurodegenerative diseases (including PD), a clear role in the disease process remains to be defined and needs to be further studied.

a-Synuclein in Parkinson's Disease

\section{Mitochondrial Dysfunction and a-syn}

Most of the $\alpha$-syn, which can selectively interact with the mitochondrial membrane, exists in the cytoplasm and part of it exists in the mitochondria. Overexpression of a-syn increases intracellular oxidative stress, changes the mitochondrial morphology, decreases the mitochondrial membrane potential, and opens mitochondrial permeability transport pores [51]. The binding of $\alpha$-syn to the mitochondrial membrane can inhibit the fusion of mitochondria and lead to mitochondrial breakage, but the overexpression of parkin, PINKl, or DJ-1 can prevent this event $[52,53]$. In terms of protein folding and aggregation, the most notable outcomes of mitochondrial dysfunction are the increase of free radical generation and the decrease of ATP production. Free radicals cause covalent modification of amino acid residues, thus destroying the native conformation of proteins [54]. The previous research suggested oxidative and nitrative stresses were involved in mechanisms underlying the pathogenesis of LBs and glial cell inclusions in PD and multiple system atrophy, respectively, as well as $\alpha$-syn pathologies in other synucleinopathies [55]. Furthermore, the researchers confirmed extensive and widespread accumulations of nitrated $\alpha$-syn in all synucleinopathy lesions including PD, dementia with Lewy bodies, and the Lewy body variant of $\mathrm{AD}$ [56]. In a word, the increased generation of oxidative and nitrative radicals is usually caused by mitochondrial dysfunction, which results in covalent modification of $\alpha$-syn, contributing to conformational change and aggregation.

As is well known, 1-methyl-4-phenyl-1,2,3,6-tetrahydropyridine (MPTP), a neurotoxin that inhibits mitochondrial complex I, is a prototype for the environmental etiology of PD because it produces a pattern of DA neurodegeneration that is closely similar to the neuropathology of PD. Dauer et al. [57] showed that in the absence of $\alpha$-syn function, the active compound 1-methyl-4-phenylpyridinium ion $\left(\mathrm{MPP}^{+}\right)$was unable to inhibit mitochondrial complex I. This conclusion was supported by two observations: (i) MPTP-induced efflux of DA was significantly reduced in the $\alpha$-syn mutant mice; (ii) $\alpha$-syn mutant mice were resistant to regimens of MPTP that resulted in different cell death patterns. With further research, it has been pointed out that the mitochondrial accumulation of a-syn is not only consistent with complex I inhibition, but also happens in concert with decreased expression of peroxisome proliferator-activated receptor gamma coactivator 1-alpha (PGC-1 $\alpha$ ), a key regulator of mitochondrial biogenesis and cellular energy metabolism, which has re-

Neurodegener Dis 2020;20:55-64 DOI: $10.1159 / 000511083$ 
cently been associated with the pathophysiology of PD. The correlation between the overexpression of $\alpha$-syn and the downregulation of PGC-1a is significant. Some evidence indicated that overexpressed $\alpha$-syn could increase mitochondrial ROS (mtROS) accumulation, mitochondrial dysfunction, and mtDNA decrement. Meanwhile, nuclear factor (erythroid-derived 2)-like 2 (Nrf2), PGC$1 \alpha$, and the cytosolic mitochondrial transcription factor A (TFAM) were upregulated to compromise mitochondrial dysfunction [58]. Consequently, the progressive accumulation of $\alpha$-syn in the brain of PD patients may impair mtDNA transcription and repair via signals from the nucleus to the mitochondria.

\section{The Relation between a-syn and Neuroinflammation in PD}

In familial $\mathrm{PD}$, various point mutations in $\alpha$-syn (A30P, E46K, H50Q, G51D, A53E, and A53T) have been identified, but there are also rare gene duplications or triploids that lead to additional autosomal-dominant or recessive forms of PD [59]. It is worth noting that the functions of glial cells (i.e., microglia, astrocytes, and oligodendrocytes) in the brain of the PD patients involved in inflammatory reactions are similar to those of peripheral immune cells. During activation, the occurrence of immune inflammation is mediated by the secretion of cytokines. A brief description of the role of the relevant cells is presented below.

\section{Astrocytes}

Astrocytes are a class of neural cells of ectodermal, neuroepithelial origin that sustain homeostasis, regulate water transport, blood flow, and synaptic transmission, and produce neurotrophic factors [60]. In the CNS, astrocytes act as an important barrier between neuronal cells and non-neuronal cells to limit the entry of white blood cells into the brain parenchyma, and they also perform other functions, such as providing energy sources for neurons, regulating synaptic activity, and regulating extracellular glutamate levels [61]. Under the stimulation of inflammatory factors, astrocytes are activated, which are characterized by the upregulation of glial fibrillary acid protein (GFAP) expression, secretion of pro-inflammatory factors, and changes in the expression of G-proteincoupled receptors (GPCRs) on astrocytes. Additionally, there is a close interaction with homocellular (astrocyteastrocyte) and heterocellular (astrocyte-other cell types) signaling and metabolism [62].
Studies have shown that the destruction of the biological function of astrocytes is related to the degeneration of dopaminergic neurons. The imbalance of neuron-glial network homeostasis has been shown to play a prominent role in the selective and progressive death of DA neurons in PD [63-65]. There are only a few reports about the activation effect of $\alpha$-syn on the astrocytes. For example, $a$-syn secreted by neurons directly acts on the astrocytes, induces inflammation, stimulates the release of IL-6, IL$1 \beta$, ICAM-1, and the expression of CXCL10. Recently, Liddelow et al. [66] reported a subdivision of the astrocytes into a destructive $\mathrm{A} 1$ and protective $\mathrm{A} 2$ phenotype. The expression of $\alpha$-syn in astrocytes in PD human brains is rather low, but $\alpha$-syn accumulated in astrocytes can produce inflammatory cytokines and chemokines, including inflammatory regulatory factors such as IFN- $\gamma$ and TNF- $\alpha[67,68]$. Meanwhile, $\alpha$-syn also interferes with glutamate transport and blood-brain barrier (BBB) function of astrocytes, resulting in significant loss of dopaminergic neurons and motoneurons. In addition, in the animal model of PD, it has been found that $a$-syn in astrocytes affects its function in many aspects [69-72].

\section{Microglia}

As the most abundant immune cells residing in the CNS, microglia interact with neurons and exhibit a wide array of functions under physiological and pathological conditions [73]. It is well known that microglia are important participants in central inflammation. They closely monitor the changes in the microenvironment around the brain and react quickly to maintain the balance of the brain microenvironment. However, although the activation of microglia plays a central role in the maintenance of normal physiological function of the brain, excessive activation can also induce a variety of neurotoxic effects $[74,75]$. Previous studies on microglia centered on their function as mediators of injury, inflammation, and neurodegeneration [76-78]. Nowadays, plenty of evidence has paid attention to the physiological functions of microglia in brain development, activity, and plasticity [79, 80].

In general, microglia-mediated inflammation is regulated by PD risk factors such as DJ-1, LRRK2, and $\alpha$-syn. Interestingly, $\alpha$-syn positively regulates microglial inflammatory responses. During PD pathology, substantial evidence suggests extracellular $\alpha$-syn directly activates microglia, which leads to significant consequences [81, $82]$. At first, $\alpha$-syn completely shifts activated microglia to exhibit a pro-inflammatory phenotype $[83,84]$. Subsequently, $\alpha$-syn-induced microglial activation promotes
He/Zhong/Liu/Yang 
$\gamma$-syn phagocytosis via $\mathrm{Fc} \gamma \mathrm{R}$ receptors, and then activates a series of pro-inflammatory events, such as NF $\gamma \mathrm{B}$ p 65 nuclear translocation and increased release of cytokines, thus potentiating the loss of neuronal loss and chronic neurodegeneration in PD [81, 85-87]. In addition, tolllike receptors (TLRs), as immunogen recognition receptors, are also involved in the inflammatory pathological changes of neurodegeneration and are closely related to the immune response induced by a-syn. For example, in microglia, $\alpha$-syn upregulates the expression of TLR2, TLR3, and TLR7, and activates the inflammatory response, but has no effect on NF- $\kappa B$ and TNF- $\alpha$ [88].

Clear evidence shows there is a bi-directional relationship between $\alpha$-syn oligomerization and the production of ROS [89]. $\alpha$-syn accumulation produces oxidative stress by activating microglia. During the overactivation of microglia, various oxygen-free radicals, such as superoxide $\left(\mathrm{O}_{2}^{-}\right)$, ROS, and cytotoxic factors such as IL-1 $\beta$, TNF- $\alpha$, and other neurotoxic substances, increased significantly, resulting in the continuous injury and apoptosis of DA neurons. Meanwhile, the release of $\alpha$-syn polymer, ATP, MMP-3, and neuromelanin from injured or apoptotic DA neurons can further promote the activation of microglia, which forms a self-advancing vicious circle and contributes to the progressive degeneration of DA neurons $[90,91]$. These findings indicate that, although activating microglia to solve cell damage is a key factor in brain homeostasis, it is clear that $\alpha$-syn-induced microglial activation leads to a variety of pro-inflammatory changes that are ultimately neurotoxic, including increased production of ROS.

In another study, however, $\alpha-$ syn $^{\mathrm{A} 53 \mathrm{~T}}$, a pathogenic form of $\alpha$-syn, was involved in promoting phagocytosis. Whereas oligomeric $\alpha$-syn acts in the opposite way [92], other studies also indicate enhanced microglial phagocytosis by fibrillar and C-terminal truncated $\alpha$-syn [93]. In summary, the conformation and pathogenic form of $\alpha$-syn play key roles in regulating the phagocytosis of microglia and the subsequent activation of inflammation, accompanying neurodegeneration in PD.

\section{Lymphocytes}

Due to the abnormal immune response to a-syn aggregation, plenty of cytokines and chemokines will not only cause heavy neuron damage, but also destroy the $\mathrm{BBB}$ and induce peripheral blood immune cells to infiltrate into the brain tissue [94]. Lymphocytes are the core of the immune response. According to the origin, morphological structure, surface markers, and immune function of lymphocytes, they can be divided into three types:
T cells, B cells, and natural killer cells (NK cells). T cells recognize these folded or aggregated proteins through antigen-presenting cells (APCs) and present them to specific T cells, thus producing cytotoxicity to DA neurons [95]. Interestingly, there were significant differences in the abundance of lymphocyte subsets in the peripheral blood of patients with PD, which indicated the change of adaptive immunity and were related to motor dysfunction [96]. In other studies, CD4+ and CD8+ T cells gathered in the substantia nigra of PD patients, CD4+ T cells affected the apoptosis of DA neurons through the Fas/ FasL pathway, and catecholamine neurons were easily attacked by CD4+ T cells [97, 98]. Shameli et al. [99] demonstrated an important role for $\alpha$-syn in the development of $\mathrm{T}$ cells and regulation of their phenotype and function in an $\alpha$-syn knockout mouse model. These studies suggest that there is a close relationship between peripheral blood lymphocyte subsets and the occurrence and development of PD. Moreover, owing to BBB dysfunction in patients with PD, $\alpha$-syn can escape from brain tissue to the blood, affecting their peripheral immune system [100].

To clarify whether PD is related to T cells recognizing a-syn epitopes presented by specific MHC alleles, Sulzer et al. [101] compared samples from 67 patients with PD and 36 healthy controls, and found that T cells in PD patients could recognize a range of peptides produced by a-syn, but this was not the case in healthy people. These findings suggest that an autoimmune response may be the underlying cause of $\mathrm{PD}$ and may also explain the relationship between PD and MHC gene variation.

Overall, it is clear that $\alpha$-syn protein fragments can induce a $\mathrm{T}$ cell-mediated immune response in patients with $\mathrm{PD}$, and it is suspected that PD may be an autoimmune disease. To what extent the risk of progression of disease may be increased in PD individuals with certain $\mathrm{MHC}$ allele configurations should be further researched.

\section{Environmental Factors and a-syn}

In the vast majority of patients with idiopathic $\mathrm{PD}$, environmental factors are also involved in the occurrence and development of the disease [102]. Epidemiological and sociological studies have shown that exposure to toxic environmental substances (such as drinking well water and exposure to agrochemicals) and specific living conditions (such as rural life and farming) increase the risk of PD [103-105]. Environmental toxins such as MPTP, rotenone, and paraquat can inhibit complex I, induce serine phosphorylation of $\alpha$-syn, and result in the formation of 


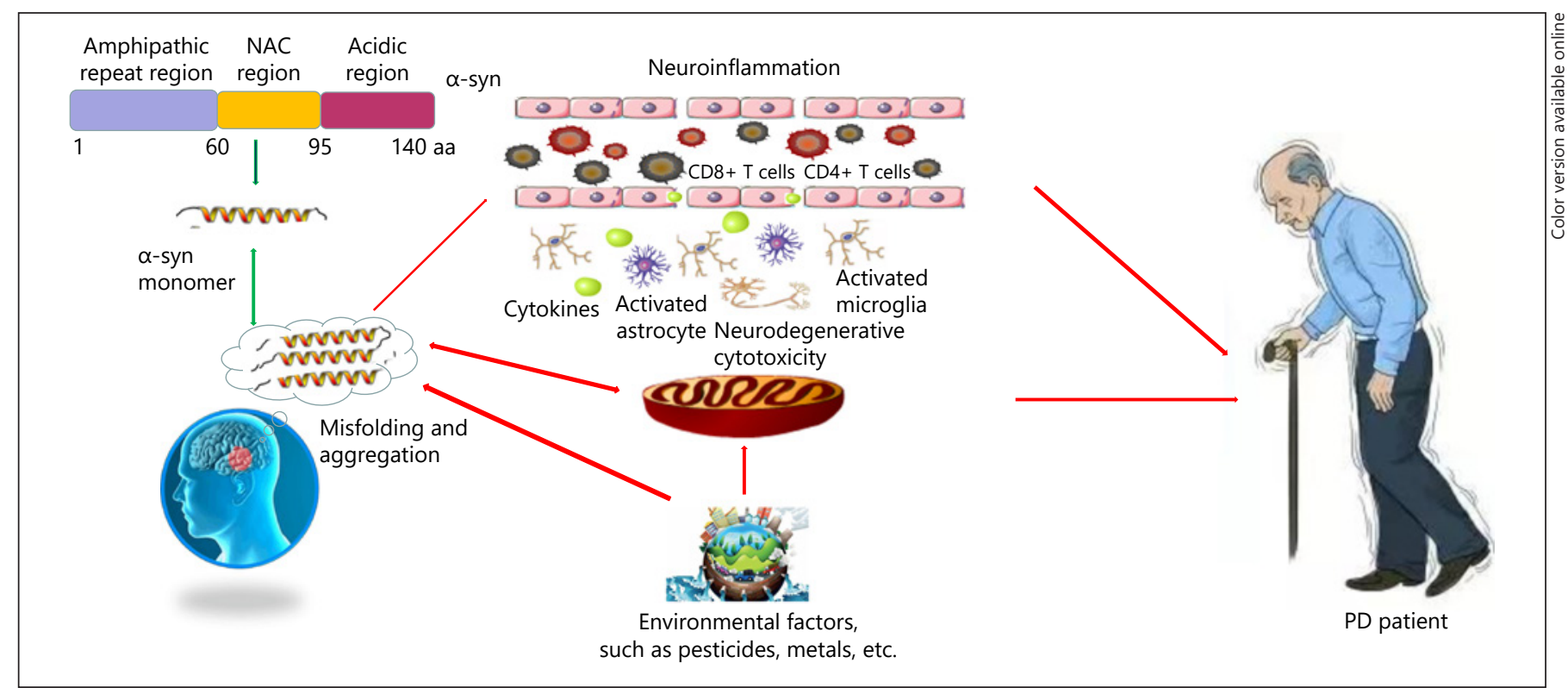

Fig. 1. Interactions among $\alpha$-syn pathology, neuroinflammation, and environmental factors in PD. Normally, $a$-syn exists as a monomer. Once misfolding and aggregation occur, it will cause the activation of astrocytes and microglia in the CNS. A large number of cytokines will destroy the BBB and induce peripheral immune cells to enter the brain, thus causing neuroinflammation.

cytoplasmic protein aggregates [106]. One of the mechanisms may be the interaction between $\alpha$-syn and other chemical species. Mohite et al. [107] studied the effect of $\mathrm{PD}$-associated toxins (DA and rotenone) on cells overexpressing wild-type (WT) and A53E (a new familial a-syn mutation), and found that cells expressing A53E showed more susceptibility to cell death along with a compromised mitochondrial potential and increased production of ROS. Meanwhile, since both genetic and environmental factors contribute to the pathogenesis of sporadic PD, a recent study investigated the susceptibility of nigrostriatal DA neurons in L444P glucocerebrosidase (GBA) heterozygous knock-in mice to MPTP, and concluded that the accompanying accumulation of $\alpha$-syn render DA neurons more susceptible to MPTP intoxication compared to WT mice [108]. These data suggest that the regulation of $\alpha$-syn as a consequence of toxicant insult and the interaction between proteins and environmental factors may be the potential mechanisms resulting in the pathology of $\alpha$-synucleinopathies.

In addition to environmental toxins such as MPTP, epidemiological studies have proposed that long-term exposure to heavy metals such as copper, lead and manganese and their combinations can increase the risk of $\mathrm{PD}$
Furthermore, mitochondrial dysfunction leads to the covalent modification of $\alpha$-syn, resulting in conformational change and aggregation. In addition, environmental factors (such as pesticides, metals, etc.) can also induce $\alpha$-syn aggregation and mitochondrial dysfunction.

[109-111]. Since they accumulate in the substantia nigra and produce oxidative stress, this leads to elevated levels of some metal ions in PD patients' brains. A populationbased study revealed that long-term exposure (more than 20 years) to copper or manganese or their combinations significantly increases the risk of PD [112]. In the same way, it was reported that individuals with lifetime lead exposure have more than a 2-fold higher risk of PD than others [113]. Interestingly, iron may be a double-edged sword. Under normal circumstances, iron is involved in the transport and storage of oxygen and ensures adequate oxygen in the brain, which is an indispensable trace element [114]. However, it has been reported that $\alpha$-synexpressing dopaminergic neurons were susceptible to the neurotoxicity of iron with age, whereby excessive iron enhanced the neurodegeneration induced by a-syn [115]. In general, all this evidence clearly shows that metal ions are involved in the progression of PD. Thus, detailed structural characterization of $\alpha$-syn-metal complexes and extensive studies on the kinetics of metal-induced $\alpha$-syn aggregation in vitro may be helpful in understanding the molecular mechanisms of synucleinopathies.

However, environmental factors may also have a dual role in regulating the modulation of disease onset, pro-
60

Neurodegener Dis 2020;20:55-64 DOI: $10.1159 / 000511083$
He/Zhong/Liu/Yang 
gression, and manifestation. Some neurotoxins can promote and accelerate the development of $\mathrm{PD}$, while others may have neuroprotective effects. Studies have reported that cigarette smoking and caffeine consumption are associated with reducing the risk of PD $[116,117]$. One proposed explanation for this effect is that they alter the composition of the intestinal microflora, thereby reducing intestinal inflammation. This, in turn, leads to less accumulation of $\alpha$-syn in the enteric nervous system, which reduces the risk of PD. Future studies will identify specific compounds or mixtures of compounds that mediate the protective effects of cigarette smoking and caffeine consumption.

\section{Conclusion}

As debated comprehensively in this review, we have a full understanding of the interaction between pathology, neuroinflammation, and environmental factors of $\alpha$-syn in PD (Fig. 1). However, several fundamental questions remain to be answered, such as the structural foundation of a-syn conformational transformation, the correlation between structural models and the cellular role of $\alpha$-syn, and the unknown endogenous cofactors (e.g., metabolites, lipids, and chaperones) that regulate the structural transformation of $\alpha$-syn upon environmental changes in diseases. Undoubtedly, future research is needed to address these challenges related to understanding the toxicity of $\alpha$-syn to neurons, which will not only provide a new way to improve the early diagnosis of PD pathology, but also contribute to the development of a comprehensive, mechanism-driven treatment.

\section{Conflict of Interest Statement}

The authors declare no conflicts of interest.

\section{Funding Sources}

This work was supported by the Young Teachers' Basic Ability Improvement Project of Guangxi (No. 2018KY0410), Guangxi Medical and Health Appropriate Technology Development and Promotion Application Project (No. S2018018).

\section{Author Contributions}

Jun Yang drew up the project. Songzhe He and Shan Zhong collected all the literature and wrote the draft primarily. Gang Liu and Jun Yang modified the manuscript. All authors read and approved the final manuscript.

\section{References}

1 Kalia LV, Lang AE. Parkinson's disease. Lancet. 2015 Aug;386(9996):896-912.

2 Parmar M, Grealish S, Henchcliffe C. The future of stem cell therapies for Parkinson disease. Nat Rev Neurosci. 2020 Feb;21(2):10315.

3 Berg D, Lang AE, Postuma RB, Maetzler W, Deuschl G, Gasser T, et al. Changing the research criteria for the diagnosis of Parkinson's disease: obstacles and opportunities. Lancet Neurol. 2013 May;12(5):514-24.

4 Burbulla LF, Song P, Mazzulli JR, Zampese E, Wong YC, Jeon S, et al. Dopamine oxidation mediates mitochondrial and lysosomal dysfunction in Parkinson's disease. Science. 2017 Sep;357(6357):1255-61.

5 Hou Y, Dan X, Babbar M, Wei Y, Hasselbalch SG, Croteau DL, et al. Ageing as a risk factor for neurodegenerative disease. Nat Rev Neurol. 2019 Oct;15(10):565-81.

6 Chinta SJ, Woods G, Demaria M, Rane A, Zou Y, McQuade A, et al. Cellular Senescence Is Induced by the Environmental Neurotoxin Paraquat and Contributes to Neuropathology Linked to Parkinson's Disease. Cell Rep. 2018 Jan;22(4):930-40.
7 Giannoccaro MP, La Morgia C, Rizzo G, Carelli V. Mitochondrial DNA and primary mitochondrial dysfunction in Parkinson's disease. Mov Disord. 2017 Mar;32(3):346-63.

8 McMillan KJ, Murray TK, Bengoa-Vergniory $\mathrm{N}$, Cordero-Llana O, Cooper J, Buckley A, et al. Loss of MicroRNA-7 Regulation Leads to a-Synuclein Accumulation and Dopaminergic Neuronal Loss In Vivo. Mol Ther. 2017 Oct;25(10):2404-14.

9 Je G, Guhathakurta S, Yun SP, Ko HS, Kim YS. A novel extended form of alpha-synuclein 3'UTR in the human brain. Mol Brain. 2018 May;11(1):29.

10 Wang C, Zhao C, Li D, Tian Z, Lai Y, Diao J, et al. Versatile structures of a-synuclein. Front Mol Neurosci. 2016 Jun;9:48.

11 Villar-Piqué A, Lopes da Fonseca T, Outeiro TF. Structure, function and toxicity of alphasynuclein: the Bermuda triangle in synucleinopathies. J Neurochem. 2016 Oct;139 Suppl 1:240-55.

12 Rocha EM, De Miranda B, Sanders LH. Alpha-synuclein: pathology, mitochondrial dysfunction and neuroinflammation in Parkinson's disease. Neurobiol Dis. 2018 Jan; 109(pt B):249-57.
13 Lashuel HA, Overk CR, Oueslati A, Masliah E. The many faces of $\alpha$-synuclein: from structure and toxicity to therapeutic target. Nat Rev Neurosci. 2013 Jan;14(1):38-48.

14 Wang Z, Gao G, Duan C, Yang H. Progress of immunotherapy of anti- $\alpha$-synuclein in Parkinson's disease. Biomed Pharmacother. 2019 Jul;115:108843.

15 Atik A, Stewart T, Zhang J. Alpha-Synuclein as a Biomarker for Parkinson's Disease. Brain Pathol. 2016 May;26(3):410-8.

16 Mollenhauer B, Locascio JJ, Schulz-Schaeffer W, Sixel-Döring F, Trenkwalder C, Schlossmacher MG. a-Synuclein and tau concentrations in cerebrospinal fluid of patients presenting with parkinsonism: a cohort study. Lancet Neurol. 2011 Mar;10(3):230-40.

17 Surguchov A. Synucleins: are they two-edged swords? J Neurosci Res. 2013 Feb;91(2):1616.

18 George JM. The synucleins. Genome Biol. 2001;3(1):reviews3002.

19 Galvin JE, Uryu K, Lee VM, Trojanowski JQ. Axon pathology in Parkinson's disease and Lewy body dementia hippocampus contains alpha-, beta-, and gamma-synuclein. Proc Natl Acad Sci USA. 1999 Nov;96(23):13450-5. 
20 Greten-Harrison B, Polydoro M, MorimotoTomita M, Diao L, Williams AM, Nie EH, et al. $\alpha \beta \gamma$-Synuclein triple knockout mice reveal age-dependent neuronal dysfunction. Proc Natl Acad Sci USA. 2010 Nov; 107(45):195738.

21 Ducas VC, Rhoades E. Quantifying interactions of $\beta$-synuclein and $\gamma$-synuclein with model membranes. J Mol Biol. 2012 Nov; 423(4):528-39.

22 Ouberai MM, Wang J, Swann MJ, Galvagnion C, Guilliams T, Dobson CM, et al. $\alpha$-Synuclein senses lipid packing defects and induces lateral expansion of lipids leading to membrane remodeling. J Biol Chem. 2013 Jul;288(29): 20883-95.

23 Akerman SC, Hossain S, Shobo A, Zhong Y, Jourdain R, Hancock MA, et al. Neurodegenerative disease-related proteins within the epidermal layer of the human skin. J Alzheimers Dis. 2019;69(2):463-78.

24 Agorogiannis EI, Agorogiannis GI, Papadimitriou A, Hadjigeorgiou GM. Protein misfolding in neurodegenerative diseases. Neuropathol Appl Neurobiol. 2004 Jun;30(3):21524.

25 Bennett MC. The role of $\alpha$-synuclein in neurodegenerative diseases. Pharmacol Ther. 2005 Mar; 105(3):311-31.

26 Abeliovich A, Schmitz Y, Fariñas I, ChoiLundberg D, Ho WH, Castillo PE, et al. Mice lacking alpha-synuclein display functional deficits in the nigrostriatal dopamine system. Neuron. 2000 Jan;25(1):239-52.

27 Conway KA, Harper JD, Lansbury PT. Accelerated in vitro fibril formation by a mutant a-synuclein linked to early-onset Parkinson disease. Nat Med. 1998 Nov;4(11):1318-20.

28 Ono K, Ikeda T, Takasaki J, Yamada M. Familial Parkinson disease mutations influence a-synuclein assembly. Neurobiol Dis. 2011 Sep;43(3):715-24.

29 Greenbaum EA, Graves CL, Mishizen-Eberz AJ, Lupoli MA, Lynch DR, Englander SW, et al. The E46K mutation in alpha-synuclein increases amyloid fibril formation. J Biol Chem. 2005 Mar;280(9):7800-7.

30 Peng C, Trojanowski JQ, Lee VM. Protein transmission in neurodegenerative disease. Nat Rev Neurol. 2020 Apr;16(4):199-212.

31 Luk KC, Kehm V, Carroll J, Zhang B, O’Brien $\mathrm{P}$, Trojanowski JQ, et al. Pathological a-synuclein transmission initiates Parkinsonlike neurodegeneration in nontransgenic mice. Science. 2012 Nov;338(6109):949-53.

32 Volpicelli-Daley LA, Luk KC, Patel TP, Tanik SA, Riddle DM, Stieber A, et al. Exogenous a-synuclein fibrils induce Lewy body pathology leading to synaptic dysfunction and neuron death. Neuron. 2011 Oct;72(1):57-71.

33 Volpicelli-Daley LA, Luk KC, Lee VM. Addition of exogenous $\alpha$-synuclein preformed fibrils to primary neuronal cultures to seed recruitment of endogenous $\alpha$-synuclein to Lewy body and Lewy neurite-like aggregates. Nat Protoc. 2014 Sep;9(9):2135-46.
34 Luk KC, Song C, O’Brien P, Stieber A, Branch JR, Brunden KR, et al. Exogenous alpha-synuclein fibrils seed the formation of Lewy bodylike intracellular inclusions in cultured cells. Proc Natl Acad Sci USA. 2009 Nov; 106(47): 20051-6.

35 Braak H, Del Tredici K, Rüb U, de Vos RA, Jansen Steur EN, Braak E. Staging of brain pathology related to sporadic Parkinson's disease. Neurobiol Aging. 2003 Mar-Apr;24(2): 197-211.

36 Braak H, Rüb U, Gai WP, Del Tredici K. Idiopathic Parkinson's disease: possible routes by which vulnerable neuronal types may be subject to neuroinvasion by an unknown pathogen. J Neural Transm (Vienna). 2003 May; 110(5):517-36

37 Kim S, Kwon SH, Kam TI, Panicker N, Karuppagounder SS, Lee S, et al. Transneuronal Propagation of Pathologic $\alpha$-Synuclein from the Gut to the Brain Models Parkinson's Disease. Neuron. 2019 Aug; 103(4):627-641.e7.

38 Polymeropoulos MH, Lavedan C, Leroy E, Ide SE, Dehejia A, Dutra A, et al. Mutation in the alpha-synuclein gene identified in families with Parkinson's disease. Science. 1997 Jun;276(5321):2045-7.

39 Krüger R, Kuhn W, Müller T, Woitalla D, Graeber M, Kösel S, et al. Ala30Pro mutation in the gene encoding alpha-synuclein in Parkinson's disease. Nat Genet. 1998 Feb;18(2): 106-8.

40 Zarranz JJ, Alegre J, Gómez-Esteban JC, Lezcano E, Ros R, Ampuero I, et al. The new mutation, E46K, of alpha-synuclein causes Parkinson and Lewy body dementia. Ann Neurol. $2004 \mathrm{Feb}$;55(2):164-73.

41 Pasanen P, Myllykangas L, Siitonen M, Raunio A, Kaakkola S, Lyytinen J, et al. Novel a-synuclein mutation A53E associated with atypical multiple system atrophy and Parkinson's disease-type pathology. Neurobiol Aging. 2014 Sep;35(9):2180.e1-5.

42 Appel-Cresswell S, Vilarino-Guell C, Encarnacion M, Sherman H, Yu I, Shah B, et al. Alpha-synuclein p.H50Q, a novel pathogenic mutation for Parkinson's disease. Mov Disord. 2013 Jun;28(6):811-3.

43 Kiely AP, Asi YT, Kara E, Limousin P, Ling H, Lewis $\mathrm{P}$, et al. $\alpha$-Synucleinopathy associated with G51D SNCA mutation: a link between Parkinson's disease and multiple system atrophy? Acta Neuropathol. 2013 May;125(5): 753-69.

44 Yoshino H, Hirano M, Stoessl AJ, Imamichi Y, Ikeda A, Li Y, et al. Homozygous alphasynuclein p.A53V in familial Parkinson's disease. Neurobiol Aging. 2017;57:248.e7-12.

45 Comellas G, Lemkau LR, Nieuwkoop AJ, Kloepper KD, Ladror DT, Ebisu R, et al. Structured regions of $\alpha$-synuclein fibrils include the early-onset Parkinson's disease mutation sites. J Mol Biol. 2011 Aug;411(4):88195.

46 Engelender S. Ubiquitination of alpha-synuclein and autophagy in Parkinson's disease. Autophagy. 2008 Apr;4(3):372-4.
47 Kaur S, Sammi SR, Jadiya P, Nazir A. RNAi of cat-2, a putative tyrosine hydroxylase, increases alpha synuclein aggregation and associated effects in transgenic C. elegans. CNS Neurol Disord Drug Targets. 2012 Jun;11(4): 387-94.

48 Jia C, Ma X, Liu Z, Gu J, Zhang X, Li D, et al. Different heat shock proteins bind $\alpha$-synuclein with distinct mechanisms and synergistically prevent its amyloid aggregation. Front Neurosci. 2019 Nov; 13:1124.

49 Tanik SA, Schultheiss CE, Volpicelli-Daley LA, Brunden KR, Lee VM. Lewy body-like $\alpha$-synuclein aggregates resist degradation and impair macroautophagy. J Biol Chem. 2013 May;288(21):15194-210

50 Meier F, Abeywardana T, Dhall A, Marotta NP, Varkey J, Langen R, et al. Semisynthetic, site-specific ubiquitin modification of a-synuclein reveals differential effects on aggregation. J Am Chem Soc. 2012 Mar;134(12): 5468-71.

51 Shen J, Du T, Wang X, Duan C, Gao G, Zhang $\mathrm{J}$, et al. $\alpha$-Synuclein amino terminus regulates mitochondrial membrane permeability. Brain Res. 2014 Dec;1591:14-26.

52 Kamp F, Exner N, Lutz AK, Wender N, Hegermann J, Brunner B, et al. Inhibition of mitochondrial fusion by $a$-synuclein is rescued by PINK1, Parkin and DJ-1. EMBO J. 2010 Oct;29(20):3571-89.

53 Ludtmann MH, Angelova PR, Horrocks MH, Choi ML, Rodrigues M, Baev AY, et al. a-synuclein oligomers interact with ATP synthase and open the permeability transition pore in Parkinson's disease. Nat Commun. 2018 Jun;9(1):2293.

54 Dean RT, Fu S, Stocker R, Davies MJ. Biochemistry and pathology of radical-mediated protein oxidation. Biochem J. 1997 May; 324(Pt 1):1-18.

55 Souza JM, Giasson BI, Chen Q, Lee VM, Ischiropoulos H. Dityrosine cross-linking promotes formation of stable $\alpha$-synuclein polymers. Implication of nitrative and oxidative stress in the pathogenesis of neurodegenerative synucleinopathies. J Biol Chem. 2000 Jun; 275(24):18344-9.

56 Giasson BI, Duda JE, Murray IV, Chen Q, Souza JM, Hurtig HI, et al. Oxidative damage linked to neurodegeneration by selective alpha-synuclein nitration in synucleinopathy lesions. Science. 2000 Nov;290(5493):985-9.

57 Dauer W, Kholodilov N, Vila M, Trillat AC, Goodchild R, Larsen KE, et al. Resistance of alpha -synuclein null mice to the parkinsonian neurotoxin MPTP. Proc Natl Acad Sci USA. 2002 Oct;99(22):14524-9.

$58 \mathrm{Fu} \mathrm{MH}, \mathrm{Wu}$ CW, Lee YC, Hung CY, Chen IC, $\mathrm{Wu}$ KL. Nrf2 activation attenuates the early suppression of mitochondrial respiration due to the $\alpha$-synuclein overexpression. Biomed J. 2018 Jun;41(3):169-83.

59 Blauwendraat C, Nalls MA, Singleton AB. The genetic architecture of Parkinson's disease. Lancet Neurol. 2020 Feb;19(2):170-8. 
60 Verkhratsky A, Nedergaard M. Physiology of Astroglia. Physiol Rev. 2018 Jan;98(1):239389.

61 Neal M, Richardson JR. Epigenetic regulation of astrocyte function in neuroinflammation and neurodegeneration. Biochim Biophys Acta Mol Basis Dis. 2018 Feb;1864(2):432-43.

62 Sofroniew MV, Vinters HV. Astrocytes: biology and pathology. Acta Neuropathol. 2010 Jan;119(1):7-35.

63 Santello M, Toni N, Volterra A. Astrocyte function from information processing to $\mathrm{cog}$ nition and cognitive impairment. Nat Neurosci. 2019 Feb;22(2):154-66.

64 Rivetti di Val Cervo P, Romanov RA, Spigolon G, Masini D, Martín-Montañez E, Toledo $\mathrm{EM}$, et al. Induction of functional dopamine neurons from human astrocytes in vitro and mouse astrocytes in a Parkinson's disease model. Nat Biotechnol. 2017 May;35(5):44452.

65 Booth HD, Hirst WD, Wade-Martins R. The Role of Astrocyte Dysfunction in Parkinson's Disease Pathogenesis. Trends Neurosci. 2017 Jun;40(6):358-70.

66 Liddelow SA, Guttenplan KA, Clarke LE, Bennett FC, Bohlen CJ, Schirmer L, et al. Neurotoxic reactive astrocytes are induced by activated microglia. Nature.2017 Jan;541(7638): 481-7.

67 Wang J, Chen Z, Walston JD, Gao P, Gao $M$, Leng SX. Interferon- $\gamma$ Potentiates a-Synuclein-induced Neurotoxicity Linked to Toll-like Receptors 2 and 3 and Tumor Necrosis Factor- $\alpha$ in Murine Astrocytes. Mo Neurobiol. 2019 Nov;56(11):7664-79.

68 Wang J, Chen Z, Walston JD, Gao P, Gao M, Leng SX. $\alpha$-Synuclein activates innate immunity but suppresses interferon- $\gamma$ expression in murine astrocytes. Eur J Neurosci. 2018 May; 48(1):1583-99.

69 Koprich JB, Kalia LV, Brotchie JM. Animal models of $\alpha$-synucleinopathy for Parkinson disease drug development. Nat Rev Neurosci. 2017 Sep;18(9):515-29.

70 Yun SP, Kam TI, Panicker N, Kim S, Oh Y, Park JS, et al. Block of A1 astrocyte conversion by microglia is neuroprotective in models of Parkinson's disease. Nat Med. 2018 Jul;24(7): 931-8

71 Beal MF. Experimental models of Parkinson's disease. Nat Rev Neurosci. 2001 May;2(5): $325-34$.

72 Zhang Y, He X, Wu X, Lei M, Wei Z, Zhang $\mathrm{X}$, et al. Rapamycin upregulates glutamate transporter and IL-6 expression in astrocytes in a mouse model of Parkinson's disease. Cell Death Dis. 2017;8(2):e2611-e. doi:https://doi. org/10.1038/cddis.2016.491.

73 Grabert K, Michoel T, Karavolos MH, Clohisey S, Baillie JK, Stevens MP, et al. Microglial brain region-dependent diversity and selective regional sensitivities to aging. Nat Neurosci. 2016 Mar;19(3):504-16.
74 Fu Y, Yang J, Wang X, Yang P, Zhao Y, Li K, et al. Herbal compounds play a role in neuroprotection through the inhibition of microglial activation. J Immunol Res. 2018 Apr;2018: 9348046.

75 Park J, Choi H, Min JS, Park SJ, Kim JH, Park $\mathrm{HJ}$, et al. Mitochondrial dynamics modulate the expression of pro-inflammatory mediators in microglial cells. J Neurochem. 2013 Oct;127(2):221-32.

76 Cartier N, Lewis CA, Zhang R, Rossi FM. The role of microglia in human disease: therapeutic tool or target? Acta Neuropathol. 2014 Sep; 128(3):363-80

77 Prinz M, Priller J. Microglia and brain macrophages in the molecular age: from origin to neuropsychiatric disease. Nat Rev Neurosci. 2014 May;15(5):300-12.

78 Prinz M, Priller J, Sisodia SS, Ransohoff RM. Heterogeneity of CNS myeloid cells and their roles in neurodegeneration. Nat Neurosci. 2011 Sep;14(10):1227-35.

79 Tay TL, Savage JC, Hui CW, Bisht K, Tremblay MẼ. Microglia across the lifespan: from origin to function in brain development, plasticity and cognition. J Physiol. 2017 Mar; 595(6):1929-45.

80 Saw G, Krishna K, Gupta N, Soong TW, Mallilankaraman K, Sajikumar S, et al. Epigenetic regulation of microglial phosphatidylinositol 3-kinase pathway involved in long-term potentiation and synaptic plasticity in rats. Glia. 2020 Mar;68(3):656-69.

81 Su X, Maguire-Zeiss KA, Giuliano R, Prifti L, Venkatesh K, Federoff HJ. Synuclein activates microglia in a model of Parkinson's disease. Neurobiol Aging. 2008 Nov;29(11):1690-701.

82 Zhang W, Wang T, Pei Z, Miller DS, Wu X, Block ML, et al. Aggregated $\alpha$-synuclein activates microglia: a process leading to disease progression in Parkinson's disease. FASEB J. 2005 Apr;19(6):533-42.

83 Austin SA, Floden AM, Murphy EJ, Combs CK. Alpha-synuclein expression modulates microglial activation phenotype. J Neurosci. 2006 Oct;26(41):10558-63.

84 Grozdanov V, Bousset L, Hoffmeister M, Bliederhaeuser C, Meier C, Madiona K, et al. Increased Immune Activation by Pathologic a-Synuclein in Parkinson's Disease. Ann Neurol. 2019 Oct;86(4):593-606.

85 Cao S, Standaert DG, Harms AS. The gamma chain subunit of $\mathrm{Fc}$ receptors is required for alpha-synuclein-induced pro-inflammatory signaling in microglia. J Neuroinflammation. 2012 Nov;9(1):259.

86 Lee EJ, Woo MS, Moon PG, Baek MC, Choi IY, Kim WK, et al. $\alpha$-synuclein activates microglia by inducing the expressions of matrix metalloproteinases and the subsequent activation of protease-activated receptor-1. J Immunol. 2010 Jul;185(1):615-23.

87 Lee SB, Park SM, Ahn KJ, Chung KC, Paik SR, Kim J. Identification of the amino acid sequence motif of alpha-synuclein responsible for macrophage activation. Biochem Biophys Res Commun. 2009 Mar;381(1):39-43.
88 Béraud D, Twomey M, Bloom B, Mittereder A, Ton V, Neitzke K, et al. $\alpha$-Synuclein alters Toll-like receptor expression. Front Neurosci. 2011 Jun;5:80.

89 Wang S, Chu $\mathrm{CH}$, Guo M, Jiang L, Nie H, Zhang W, et al. Identification of a specific $\alpha$-synuclein peptide ( $\alpha$-Syn 29-40) capable of eliciting microglial superoxide production to damage dopaminergic neurons. J Neuroinflammation. 2016 Jun;13(1):158.

90 Kelly R, Joers V, Tansey MG, McKernan DP, Dowd E. Microglial Phenotypes and Their Relationship to the Cannabinoid System: Therapeutic Implications for Parkinson's Disease. Molecules. 2020 Jan;25(3): 453.

91 Hammond TR, Dufort C, Dissing-Olesen L, Giera S, Young A, Wysoker A, et al. SingleCell RNA Sequencing of Microglia throughout the Mouse Lifespan and in the Injured Brain Reveals Complex Cell-State Changes. Immunity. 2019 Jan;50(1):253-271.e6.

92 Park JY, Paik SR, Jou I, Park SM. Microglial phagocytosis is enhanced by monomeric a-synuclein, not aggregated $a$-synuclein: implications for Parkinson's disease. Glia. 2008 Aug;56(11):1215-23.

93 Fellner L, Irschick R, Schanda K, Reindl M, Klimaschewski L, Poewe W, et al. Toll-like receptor 4 is required for $\alpha$-synuclein dependent activation of microglia and astroglia. Glia. 2013 Mar;61(3):349-60.

94 Jiao Z, Zhang W, Chen C, Zhu X, Chen X, Zhou M, et al. Gene Dysfunction Mediates Immune Response to Dopaminergic Degeneration in Parkinson's Disease. ACS Chem Neurosci. 2019 Feb;10(2):803-11.

95 Schetters ST, Gomez-Nicola D, GarciaVallejo JJ, Van Kooyk Y. Neuroinflammation: microglia and T cells get ready to tango. Front Immunol. 2018 Jan;8:1905.

96 Saunders JA, Estes KA, Kosloski LM, Allen HE, Dempsey KM, Torres-Russotto DR, et al. CD4+ regulatory and effector/memory T cell subsets profile motor dysfunction in Parkinson's disease. J Neuroimmune Pharmacol. 2012 Dec;7(4):927-38.

97 Brochard V, Combadière B, Prigent $\mathrm{A}, \mathrm{La}-$ ouar Y, Perrin A, Beray-Berthat V, et al. Infiltration of $\mathrm{CD} 4+$ lymphocytes into the brain contributes to neurodegeneration in a mouse model of Parkinson disease. J Clin Invest. 2009 Jan;119(1):182-92.

98 Cebrián C, Zucca FA, Mauri P, Steinbeck JA, Studer L, Scherzer CR, et al. MHC-I expression renders catecholaminergic neurons susceptible to T-cell-mediated degeneration. Nat Commun. 2014 Apr;5(1):3633.

99 Shameli A, Xiao W, Zheng Y, Shyu S, Sumodi J, Meyerson HJ, et al. A critical role for alpha-synuclein in development and function of $\mathrm{T}$ lymphocytes. Immunobiology. 2016 Feb;221(2):333-40.

100 Sui YT, Bullock KM, Erickson MA, Zhang J, Banks WA. Alpha synuclein is transported into and out of the brain by the blood-brain barrier. Peptides. 2014 Dec;62:197-202. 
101 Sulzer D, Alcalay RN, Garretti F, Cote L, Kanter E, Agin-Liebes J, et al. T cells from patients with Parkinson's disease recognize a-synuclein peptides. Nature. 2017 Jun; 546(7660):656-61.

102 Emamzadeh FN, Surguchov A. Parkinson's disease: biomarkers, treatment, and risk Factors. Front Neurosci. 2018 Aug; 12:612.

103 Lai BC, Marion SA, Teschke K, Tsui JK. Occupational and environmental risk factors for Parkinson's disease. Parkinsonism Relat Disord. 2002 Jun;8(5):297-309.

104 Gatto NM, Cockburn M, Bronstein J, Manthripragada AD, Ritz B. Well-water consumption and Parkinson's disease in rural California. Environ Health Perspect. 2009 Dec;117(12):1912-8.

105 Klingelhoefer L, Reichmann H. Pathogenesis of Parkinson disease-the gut-brain axis and environmental factors. Nat Rev Neurol. 2015 Nov;11(11):625-36.

106 Liu Y, Yang H. Environmental toxins and alpha-synuclein in Parkinson's disease. Mol Neurobiol. 2005;31(1-3):273-82.

107 Mohite GM, Navalkar A, Kumar R, Mehra S, Das S, Gadhe LG, et al. The Familial a-Synuclein A53E Mutation Enhances Cell
Death in Response to Environmental Toxins Due to a Larger Population of Oligomers. Biochemistry. 2018 Aug;57(33):5014-28.

108 Yun SP, Kim D, Kim S, Kim S, Karuppagounder SS, Kwon SH, et al. a-Synuclein accumulation and GBA deficiency due to L444P GBA mutation contributes to MPTPinduced parkinsonism. Mol Neurodegener. 2018 Jan;13(1):1.

109 Ghosh D, Mehra S, Sahay S, Singh PK, Maji SK. $\alpha$-Synuclein aggregation and its modulation. Int J Biol Macromol. 2017 Jul;100: 37-54.

110 Chin-Chan M, Navarro-Yepes J, Quintanilla-Vega B. Environmental pollutants as risk factors for neurodegenerative disorders: alzheimer and Parkinson diseases. Front Cell Neurosci. 2015 Apr;9:124.

111 Uversky VN, Li J, Fink AL. Metal-triggered structural transformations, aggregation, and fibrillation of human alpha-synuclein. A possible molecular NK between Parkinson's disease and heavy metal exposure. J Biol Chem. 2001 Nov;276(47):44284-96.

112 Gorell JM, Johnson CC, Rybicki BA, Peterson EL, Kortsha GX, Brown GG, et al. Occupational exposures to metals as risk fac- tors for Parkinson's disease. Neurology. 1997 Mar;48(3):650-8.

113 Coon S, Stark A, Peterson E, Gloi A, Kortsha G, Pounds J, et al. Whole-body lifetime occupational lead exposure and risk of Parkinson's disease. Environ Health Perspect. 2006 Dec;114(12):1872-6.

114 Zheng W, Monnot AD. Regulation of brain iron and copper homeostasis by brain barrier systems: implication in neurodegenerative diseases. Pharmacol Ther. 2012 Feb; 133(2):177-88.

115 Patel D, Xu C, Nagarajan S, Liu Z, Hemphill WO, Shi R, et al. Alpha-synuclein inhibits Snx3-retromer-mediated retrograde recycling of iron transporters in S. cerevisiae and C. elegans models of Parkinson's disease. Hum Mol Genet. 2018 May;27(9):1514-32.

116 Derkinderen P, Shannon KM, Brundin P. Gut feelings about smoking and coffee in Parkinson's disease. Mov Disord. 2014 Jul; 29(8):976-9.

117 Scheperjans F, Pekkonen E, Kaakkola S, Auvinen P. Linking smoking, coffee, urate, and Parkinson's disease - a role for gut microbiota? J Parkinsons Dis. 2015;5(2):25562. 